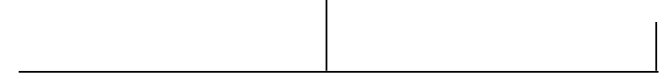

Rev. Latinoam. Psicopat. Fund., São Paulo, v. 12, n. 1, p. 161-166, março 2009

\title{
Kraepelin e a questão da manifestação clínica das doenças mentais
}

\author{
Mário Eduardo Costa Pereira
}

No artigo de 1920 intitulado "Die Erscheinungsformen des Irreseins", publicado já na maturidade teórica de Kraepelin, o grande autor alemão propõe uma releitura de suas concepções sobre a psicopatologia, considerando que as manifestações clínicas das doenças mentais não são jamais expressão direta dos processos mórbidos subjacentes. Elas dependem de uma complexa interação com o sujeito e sua história, no qual tal alteração se instala e inscreve.

Palavras-chave: Kraepelin, psicopatologia, doenças mentais - formas de manifestação, processos mórbidos 
"Die Erscheinungsformen des Irreseins" - "As formas de manifestação da insanidade" - publicado em 1920 no Zeitschrift für die gesamte Neurologie und Psychiatrie, constitui um artigo particularmente importante e esclarecedor para a compreensão do ponto de vista kraepeliniano sobre as expressões clínicas concretas da doença mental. Trata-se de um artigo da maturidade de Kraepelin, que contava, na época da publicação, com 64 anos de idade, vindo a falecer apenas seis anos mais tarde. Nessa época, todas as oito edições de seu Lehbuch der Psychiatrie já haviam sido publicadas e o grande alienista alemão já havia realizado suas viagens de pesquisa a países como Índia, Turquia, Egito, Itália, a Java, aos Estados Unidos e ao México para efetuar suas investigações sobre os elementos invariantes das manifestações dos transtornos mentais em diferentes culturas, no contexto da "psiquiatria comparativa" com a qual Kraepelin pretendia esclarecer a natureza do adoecer psíquico. Como se sabe, dessas investigações etnopsiquiátricas, Kraepelin chega à conclusão de que "a Dementia praecox é uma entidade universal, inerente à condição humana, e independente das vicissitudes geográficas ou raciais. Apenas os aspectos secundários da doença sofreriam a ação da cultura" (Dalgalarrondo, 1996, p. 85). Daí sua insistência em distinguir os elementos constituintes da doença mental de suas manifestações clínicas (Erscheinungsformen). Kraepelin visava, assim, o ideal de isolar o núcleo mórbido propriamente médico-biológico da loucura de suas expressões visíveis transformadas pela cultura, pela história e pela subjetividade.

Ao longo de sua obra, Kraepelin desenvolve os princípios propostos por Kahlbaum já em 1874, segundo os quais uma classificação de transtornos mentais deveria se basear na sintomatologia, na evolução e no prognóstico de cada entidade clínica isolada (cf. Angst, 2007). Dessa maneira, o projeto nosográfico kraepeliniano é fundamentalmente categorial, ou seja, as entidades diagnósticas deveriam ser descritas idealmente como unidades mórbidas isoladas, claramente delimitadas em oposição às demais. Não havia lugar, em seu sistema, para a concepção dimensional dessas perturbações psíquicas, segundo a qual haveria uma continuidade gradual entre diferentes manifestações psicopatológicas, sendo nitidamente distintos apenas os estados extremos dos processos doentios mentais. Uma expressão maior de seu esforço por estabelecer as fronteiras nítidas separando as diferentes espécies de doença mental foi sua clássica distinção entre a Dementia precox e a Loucura Maníaco-Depressiva. Quando, 
modernamente, certos autores referem-se aos modelos classificatórios contemporâneos em psiquiatria como sendo "neo-kraepelinianos", aludem com essa expressão à sua característica de tentar isolar sobre bases sintomatológicas objetiváveis entidades mórbidas nitidamente distintas.

O artigo de 1920, aqui comentado, constitui um momento decisivo de reexame e de reelaboração, realizado na maturidade da obra de Kraepelin, em relação a algumas de suas proposições fundamentais até ali sustentadas.

O mestre de Munique inicia seu argumento relembrando que muitos críticos da época apontavam para o fato de que a pesquisa em psiquiatria clínica teria chegado a um ponto de estagnação, permanecendo excessivamente centrada em seus esforços descritivos e classificatórios, mas negligenciando "a tarefa indubitavelmente mais elevada e gratificante de conseguir uma compreensão sobre a essência e as conexões internas dos processos patológicos". Esse era o novo desafio metodológico ao qual a psiquiatria deveria se confrontar: compreender a psicopatologia não apenas como catálogo racionalmente organizado de formas clínicas isoladas, mas, sobretudo, como expressão "de determinados pressupostos, descobrindo as leis que regem seu aparecimento".

Não se trata, contudo, no artigo de Kraepelin, de explicitar as bases físicas da doença mental, mas de estabelecer as condições teóricas e clínicas para a compreensão de suas formas de manifestação. Ele evoca, por exemplo, o fato de que mesmo situações patológicas que apresentam danos exteriores totalmente evidentes têm manifestações individuais muito diferentes em diferentes pacientes, o que demonstra que "estes danos incidem sobre um órgão que tem por trás de si características pessoais infinitamente ricas e de ordem histórico-hereditária". Dito em outras palavras, o quadro psicopatológico não pode em nenhum caso ser concebido como uma expressão direta de um processo mórbido de natureza biológica. O sintoma mental observável não pode ser considerado mera manifestação da lesão.

É interessante notar que apesar de reiterar nesse artigo sua posição nitidamente antipsicanalítica, Kraepelin recorre inúmeras vezes ao longo do texto a argumentos de matiz nitidamente freudiana para tentar dar conta das variações individuais na manifestação dos estados psicopatológicos. Assim, por exemplo, ele explica que as fantasias de posse de fortuna, típicas da neuro-sífilis, não poderiam ser compreendidas como expressão direta da doença, mas como liberação "dos desejos do paciente"! Ou ainda, em inúmeras situações, a doença permitiria a manifestação de traços de memória "muitas vezes sujeitos a intensa repressão e transformação", sendo, portanto, que as expressões observáveis no plano clínico corresponderiam a esforços do indivíduo para lidar com tais elementos até ali mantidos ocultos. 
Dessa maneira, Kraepelin propõe aqui uma concepção da manifestação clínica das doenças mentais como resultantes da interação entre déficits e alterações decorrentes de processos mórbidos subjacentes (em geral de natureza biológica) e "das pré-condições existentes no sujeito". Nos casos em que "desenvolvimentos anormais" (na clássica oposição entre "desenvolvimentos", de natureza históricoindividual e "processos", como rupturas mórbidas repentinas da continuidade da experiência vital) constituem a base da condição psicopatológica, então a origem do quadro mental deve ser buscada inteiramente "nas insuficiências da personalidade psíquica”.

O grande autor alemão propõe, assim, um estudo da psicopatologia que integre a pesquisa de fatores biológicos alterados, dos encadeamentos individuais de ordem psíquica e da história pregressa do indivíduo.

Além disso, Kraepelin admite que "os transtornos de base provocados diretamente pela causa da patologia (...) também devem estar sujeitos a consideráveis gradações e oscilações". Isso, combinado ao fato de que existem "tonalidades genéricas próprias com as quais o indivíduo responde aos transtornos das mais variadas espécies", conduz à conclusão segundo a qual "somos forçados a restringir ao máximo o pressuposto de que este ou aquele transtorno é característico de um determinado processo patológico".

Mesmo assim, cada doença deve ter suas próprias particularidades e "devemos supor, sim, que a um determinado sofrimento correspondam determinadas formas de manifestação - não porque os processos patológicos os provoquem diretamente, mas porque, segundo a experiência, eles criam condições que são muito propícias ao surgimento dessas manifestações". Observamos, assim, que Kraepelin, tido como um dos pilares de sustentação da noção de "doença mental" em psicopatologia, é conduzido a concebê-la de forma dialética em relação à história e às características individuais do paciente, pressupondo a singularidade e o sujeito, enquanto tal, como referências indispensáveis para a compreensão das manifestações da psicopatologia.

\section{Referências}

Angst, J. Psychiatric diagnoses: the weak component of modern research. World Psychiatry., v. 6, n. 2, p. 94-95, 2007 Jun.

BERCHERIE, P. Histoire et structure du savoir psychiatrique: les fondements de la clinique - I. Tournai: Editions Universitaires, 1991.

Berrios, G. The history of the mental symptoms. Cambridge: Cambridge Univ. Press, 1996. 
Dalgalarrondo, P. A psiquiatria transcultural de Kraepelin. In: Civilização e loucura: uma introdução à história da etnopsiquiatria. São Paulo: Lemos, 1996. p. 83-93. Garrabe, J. Histoire de la schizophénie. Paris: Seghers, 1992.

Kraepelin, E. Introduction à la psychiatrie clinique. Paris: Navarin, 1984. . La demencia precoz - vol. I e II. Buenos Aires: Polemos Editorial, 1996.

Pereira, M. E. C. Kraepelin e a criação do conceito de "Demência precoce". Revista Latinoamericana de Psicopatologia Fundamental, São Paulo, v. IV, n. 4, p. 126-129, dez. 2001.

Pichot, P.; Rein, W. (Eds.). The clinical approach in psychiatry. Le PlessisRobinson: Synthélabo, 1992.

Postel, J.; Quetel, C. (Orgs.). Nouvelle histoire de la psychiatrie. Toulouse: Privat, 1983.

Stagnaro, J. C. Presentation a Kraepelin, E. La demencia precoz - vol. I. Buenos Aires: Polemos Editorial, 1996. p. VII-XXIII.

(Kraepelin y la cuestión de la manifestación clínica de las enfermedades mentales)

En el artículo de 1920 titulado "Die Erscheinungsformen des Irreseins" publicado en la madurez teórica de Kraepelin, el gran autor alemán propone una relectura de sus concepciones sobre la psicopatología, considerando que las manifestaciones clínicas de las enfermedades mentales no son jamás expresión directa de los procesos mórbidos subyacentes. Ellas dependen de una compleja interacción con el sujeto y su historia, en la cual tal alteración se instala e inscribe.

Palabras claves: Kraepelen, psicopatología, enfermedades mentales - formas de manifestación, procesos mórbidos

(Kraepelin et la question de la manifestation clinique des maladies mentales)

Dans l'article de 1920, intitule "Die Erscheinungsformen des Irreseins", publié à la maturité théorique de Kraepelin, le grand auteur allemand propose une relecture de ses propres conceptions sur la psychopathologie, selon laquelle il considère que les manifestations cliniques ne constituent jamais l'expression directe des processus morbides sous-jacents. Elles dépendend d'une intéraction complexe avec le sujet et son histoire, dans laquelle cette alteration s'installe et s'inscrit.

Mots clés: Kraepelin, psychopathologie, maladies mentales - formes de manifestation, processus morbides 
(Kraepelin and the question of the clinical manifestation of mental diseases)

In an article of 1920 entitled "Die Erscheinungsformen des Irreseins," published in Kraepelin's phase of theoretical maturity, this great German scholar presented a rereading of his thinking on psychopathology, considering that clinical manifestations of mental diseases are never direct expressions of underlying pathogenic processes. Manifestations depend on a complex interaction with the subject in his or her history during which changes have been installed and inscribed.

Key words: Kraepelin, psychopathology, mental disease - forms of manifestation, pathological processes

Citação/Citation: Pereira, M.E.C. Kraepelin e a questão da manifestação clínica das doenças mentais. Revista Latinoamericana de Psicopatologia Fundamental, São Paulo, v. 12, n. 1, p. 161-166, mar. 2009.

Editor do artigo/Editor: Prof. Dr. Mario Eduardo Costa Pereira.

Recebido/Received: 13.2.2009/2.13.2009 Aceito/Accepted: 13.2.2009 / 2.13.2009

Copyright: (C) 2009 Associação Universitária de Pesquisa em Psicopatologia Fundamental/ University Association for Research in Fundamental Psychopathology. Este é um artigo de livre acesso, que permite uso irrestrito, distribuição e reprodução em qualquer meio, desde que o autor e a fonte sejam citados/This is an open-access article, which permits unrestricted use, distribution, and reproduction in any medium, provided the original author and source are credited.

Financiamento/Funding: $\mathrm{O}$ autor declara não ter sido financiado ou apoiado/The author has no support or funding to report.

Conflito de interesses: $\mathrm{O}$ autor declara que não há conflito de interesses/The author declares that has no conflit of interest.

\section{Mario Eduardo Costa Pereira}

Psiquiatra, psicanalista e professor Livre-Docente de Psicopatologia do Depto. de Psicologia Médica e Psiquiatria da Universidade Estadual de Campinas - Unicamp (Campinas, SP, Brasil); doutor em Psicopatologia Fundamental e Psicanálise pela Universidade Paris 7; diretor do Laboratório de Psicopatologia Fundamental da Unicamp; membro do Laboratoire de Psychopathologie Clinique et Psychanalyse da Universidade de Provence.

Rua Carolina Prado Penteado, 725 - Nova Campinas

13092-470 Campinas, SP, Brasil

Fone: (19) 3254-5064 / 3254-1982 / 3289-4819 (Unicamp)

e-mail: marioecpereira@uol.com.br 